\title{
FORMAÇÃO DE UM DUPLO NARCISO OU ANGÚSTIA EM TERRA ESTRANGEIRA
}

\author{
Marcela Jussara Miwa *
}

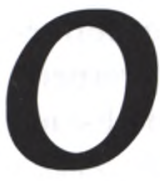

narcisismo pode ser compreendido como uma defesa do ego ao depararse com o diferente, o estranho ou frustrações. Tal defesa recorre a mecanismos, por vezes inconscientes, de negação da realidade - ou do outro - buscando refúgio em idealizações, fantasias, dissociando-se da realidade (ver p. ex. Rosenfeld, 1989 e Symington, 2003). O presente texto procura ilustrar como, no período da imigração japonesa, podem-se localizar dois grupos distintos com defesas narcísicas. De um lado, os brasileiros da campanha antinipônica, o que denomino "narcisismo verdeamarelo", que negavam, e mesmo, rejeitavam os estranhos japoneses. E por outro lado, até como reação ao antiniponismo e aos problemas de adaptação, os imigrantes, que não aceitavam a realidade brasileira e refugiavam-se em colônias, cultivando valores da pátria que deixaram, idealizando um Japão poderoso. Nas linhas seguintes pretendo retomar algumas passagens tanto do movimento antinipônico, como também dos primeiros anos das vidas dos japoneses, em nosso país, no intuito de demonstrar a possibilidade de reler esses eventos históricos como mecanismos de defesa egóica.

\section{JAPONESES NO BRASIL}

Nos fins do século XIX e início do $\mathrm{XX}$, o Brasil encontrava-se em meio a grandes debates sobre a questão racial. As brasas de uma recém abolida escravidão ainda ardiam na sociedade, a preocupação com massas de negros livres e a crescente vinda de braços europeus acenderam os ímpetos pela formação de uma raça e integridade nacionais. As populações mestiças passaram a ser vistas como indício de degeneração étnico-social. Os imigrantes europeus seriam aclamados de grande valia para a aceleração do "embranquecimento" nacional.

Entretanto, começava a surgir uma grande insatisfação entre os cafeicultores em relação aos trabalhadores europeus, pois não eram poucos os que abandonavam as lavouras para se dedicarem a outras atividades ou, quando era possível, retornavam a seu país de origem.

Diante de clamores dos produtores de café por braços em suas terras, organizou-se um grupo para pressionar o governo a fim de solucionar o problema. Seus apelos surtiram efeito pois, em 1892, sancionou-se uma lei em que o Brasil comprometia-se a sustentar relações diplomáticas com a China e o Japão, no intuito de angariar trabalhadores para as plantações brasileiras. Todavia, a vinda de japoneses ainda demoraria alguns anos, uma vez que nesse acordo os grandes privilegiados foram os chineses, considerados "superiores" aos nipônicos.

Essa "inferioridade" dos japoneses foi ignorada pelos latifundiários brasileiros em pouco tempo, já que em 1902 , os cafeicultores foram surpreendidos pela proibição da vinda de braços italianos para a lavoura. $\mathrm{O}$ Congresso italiano proibiu a imigração de seus "filhos" devido a desumanidade com que eram tratados nas fazendas. Tal fato contribuiu imensamente para facilitar a contratação de trabalhadores japoneses, iniciada em 1908.

\section{NARCISISMO VERDE-AMARELO}

A partir de 1920 o número de imigrantes nipônicos, no Brasil, aumentou de forma impressionante, em boa parte impulsionada pelo próprio governo japonês, que se esforçava em 
superar inúmeros problemas, entre eles, a escassez de alimentos. Tal fato desencadeou uma reação brasileira ante a "invasão amarela".

Independentemente de serem considerados bons trabalhadores ou não, uma campanha antinipônica tomou corpo e gerou diversos debates no Congresso Nacional. Médicos como Xavier de Oliveira, Miguel Couto, Arthur Neiva ${ }^{1}$, o jornalista e escritor Vivaldo Coaracy, o major Aristóteles de Lima Câmara e o sociólogo, historiador e jurista Oliveira Vianna foram ferrenhos opositores da imigração japonesa, pautados em argumentos considerados científicos, e grandes defensores da integridade do pais.

Oliveira Vianna, por exemplo, alegava que os orientais constituíam uma "raça" inferior além de serem "inassimiláveis" (Vianna, 1934). E não estava sozinho, existiam muitas vozes que clamavam por ações contra os "inimigos" japoneses. Muitos defendiam discursos racistas de "depuração" da suposta raça brasileira, encontrando força na política nacionalista do período Vargas. Essa polêmica atingiu o ápice nos acalorados debates da Assembléia Constituinte entre 1933 e 1934, da qual resultou a emenda Miguel Couto pela redução da entrada de imigrantes, estabelecendo quotas de imigração. Essa emenda visava a restringir principalmente a vinda de japoneses, que por esse período chegavam em grandes levas ${ }^{2}$.

A incompreensão e o crescimento desmedido do número de colonos nipônicos favoreceram o incitamento de discursos inflamados durantes a elaboração da Constituição de 1934.

$\mathrm{O}$ médico psiquiatra Xavier de Oliveira ${ }^{3}$ combateu a entrada de qualquer raça considerada eugenicamente indesejável, o que incluía os diferentes japoneses.
Além das peculiaridades físicas nítidas, os médicos antinipônicos recorriam a outros argumentos para rejeitarem o "elemento amarelo". Como o discurso de Arthur Neiva, que se baseava nas precárias condições de saúde desses imigrantes, disseminadores de novas doenças no Brasil e desqualificados do ponto de vista "antropo-estético", defendendo o imigrante branco como ideal (cf. Nucci, 2000: 48).

Quanto a doenças, considerando que as viagens de navio entre Japão e Brasil duravam cerca de 50 dias e assim que entravam nas fazendas as condições de trabalho não eram das melhores, imagina-se que a saúde dos japoneses só poderia apresentar-se debilitada. Não foram poucos aqueles que, já instalados no Brasil, morreram de malária ou perderam os familiares por essa doença.

Miguel Couto, que emprestou seu nome à emenda de 1934, também rechaçava a vinda de japoneses, porém preferia atribuir essa atitude muito mais a um amor à pátria do que uma oposição declarada aos nipônicos.

Falando em defesa nacional não podemos esquecer que o governo nacionalista de Getúlio Vargas pesou como um flagelo sobre os imigrantes, principalmente nos anos próximos à segunda guerra mundial, em que a perseguição aos imigrantes provenientes do Eixo tornou-se mais acirrada. Esses imigrantes foram privados dos meios de comunicação em sua língua, ou seja, rádio, jornais, livros e revistas em língua estrangeira. Conversar em outra língua que não fosse português, já era motivo de prisão.

Para a grande maioria dos imigrantes japoneses a educação de seus filhos, em moldes nipônicos, transformou-se em um tormento, para não dizer um engenho arriscado. Os policiais adentravam nas casas e estabelecimentos desses imigrantes em busca de algo que denunciasse a insubordinação, reviravam tudo em busca de livros, cartilhas ou cadernos escritos em japonês. A clandestinidade era a única saída para pais, alunos e professores nipônicos.

A vigilância sobre os considerados "súditos do eixo" era constante. A incompreensão e o preconceito em relação ao diferente também permearăm os relatórios policiais, isto é perceptível quando afirmavam: "dadas as dificuldades decorrentes da diversidade da língua e da índole hipocritamente dócil do indivíduo japonês, torna-se difícil o conhecimento exato de tudo que diz respeito ao nipônico (...)" (Arquivo do Estado de São Paulo/SP, prontuário n ${ }^{\circ} 8342$ Niponismo).

A "docilidade" nipônica, que em outros momentos poderia ser aclamada como uma virtude desse povo, em tempos de guerra e antiniponismo soa como hipocrisia, dissimulação de intenções covardes e perigosas à integridade nacional.

Falando do período de guerras, em 1940, em meio aos conflitos da segunda guerra mundial, desponta outra obra antinipônica, denominada $O$ perigo japonês, que traz artigos do jornalista e escritor Vivaldo Coaracy. Esses artigos, além de retomarem os velhos argumentos dos antinipônicos das décadas de 1920 e 30 , conquistaram maior espaço ao apresentarem sua oposição e temor em relação ao projeto imperialista japonês. Não eram raros os que acreditavam que os imigrantes japoneses eram integrantes do exército nipônico, disfarçados de simples agricultores, que obedeciam as estratégias de seu governo e estavam apenas aguardando o melhor momento para conquistarem as terras brasileiras. 
Alguns imigrantes até deixaram-se seduzir por essas idéias, sentindo orgulho por terem iniciado a colonização nas longínquas terras que logo "pertenceriam" a seu grande império. $\mathrm{Na}$ verdade não passaram de devaneios, de sonhos nos quais esses meros trabalhadores ganhavam importância aos olhos daqueles que permaneceram no "berço esplêndido" de seu país de origem. Quando pensavam na honrosa função a desempenhar, qual seja, a de conquistar os territórios de além-mar, os imigrantes não se sentiam mais sozinhos, abandonados ou esquecidos; seus peitos acompanhavam o ritmo entoado por outros corações, fisicamente distantes, mas espiritualmente interligados.

Entretanto, ao resgatar as histórias desses imigrantes fica evidente que não se tratavam de tropas especiais enviadas estrategicamente em terras ocidentais, como ficou subentendido acima. Os ideais de conquista e prosperidade serviam apenas como uma "fuga" desses imigrantes, como um atenuante das dores que o álcool por vezes ajudava a anestesiar. Suas vidas estavam longe de participar da campanha imperialista do grande império japonês. Sua realidade era bem diferente. Tiveram, muitas vezes, de enfrentar os preconceitos, a incompreensão, o descaso, injustiças e, como golpe fatal, a tristeza de ver seu país derrotado.

Passemos às histórias desses imigrantes.

\section{JAPONESES NO JAPÃO}

Uma das grandes contribuições dos samurais para a história japonesa foi o bushidô ou Código de Honra dos Samurais, constituído de regras de conduta, conselhos e técnicas marciais e até mesmo estéticas, que não tardaram por se disseminar entre outras classes e camadas da população nipônica. Apesar do imenso poder político e territorial que os shoguns ${ }^{4}$ possuíam, a figura do imperador continuou sendo preservada. Esse respeito ao trono e à família imperial foi assegurado, em grande parte, pelo código de honra dos guerreiros e por certas concepções religiosas - por exemplo, xintoísmo: pregava lealdade ao soberano (visto como descendente da Deusa do Sol, Amaterasu Oomikami) e o confucionismo defendia a hierarquia como algo natural. Os shoguns assumiam o poder mediante autorização, nomeação, indicação ou rescrito do soberano.

Durante o shogunato Tokugawa Bakufu (1603-1868), o Japão passou por uma época de grande concentração de poder interno, uma vez que inexistiam relações e influências estrangeiras. Por esse isolamento, o país conseguiu assegurar relativa paz interna e evitou dispêndio de recursos em aventuras em outras terras. Todavia, essa aconchegante paz levou a nação a certa imobilidade, que a tornou atrasada em relação ao "progresso mundial", de expansão colonial das potências marítimás. E antes mesmo da queda do shogunato em 1868, o Japão foi pressionado a abrir seus portos para o comércio internacional. Tal fato possibilitou que muitos japoneses, que se encontravam em estado de penúria, saíssem do país em busca de uma vida melhor. Em 1850 ocorreram as primeiras emigrações para o Havaí, depois os Estados Unidos, Peru, México e Brasil, a partir de 1908.

Quando os nipônicos começaram a vir ao Brasil, a "situação de pobreza" em seu país parecia superada. A Restauração Meiji (1868-1912) inaugurou uma nova fase na vida de seus súditos. O Japão vivenciou uma "corrida" pelo desenvolvimento, no afã de sair do atraso que os anos do shogunato relegaram ao país.

Se por um lado uma boa parte da população desfrutou do deslumbre das facilidades capitalistas; por outro lado, houve os que sofreram com o novo governo. Muitos dos antigos samurais caíram na miséria, outros tantos ajeitaram-se como puderam diante da nova realidade. A população mais pobre começou a manifestar seu descontentamento, através de rebeliões. Protestavam basicamente por três motivos: o imposto rural, a convocação ao serviço militar obrigatório e o sistema educacional, também obrigatório.

Os avanços imperialistas do governo japonês oneravam a população. As vitórias nas guerras contra China (1894) e a Rússia (1904), e conseqüente euforia do triunfo, contribuíram para abafar as queixas daqueles que não conseguiam acompanhar o progresso nacional. $\mathrm{O}$ estado de ânimo e a prosperidade econômica facilitaram a explosão demográfica.

E foi nesse contexto, de convicção do triunfo bélico em seu peito e de miséria em seus pratos, que fez com que muitos japoneses decidissem transpor os mares e tentar a sorte em terras brasileiras. A emigração não era um interesse apenas de quem partia, mas configurou-se como um esforço do próprio governo.

\section{ANGÚSTIA EM TERRA ESTRANGEIRA}

Fustigados pela pobreza e sedentos por um enriquecimento fácil e rápido, muitos nipônicos desfizeram-se do pouco que tinham para financiar a nova empreitada. Famílias contraíram dívidas para bancarem a viagem de 
seus parentes. Prejuízos que deveriam ser pagos através de remessas de dinheiro daqueles que partiam. Tratava-se de uma questão de honra saldá-los. Todos acalentavam a esperança de em breve retornarem ao Japão, ricos e triunfantes. Deixavam sua pátria como "heróis" sem imaginar as dificuldades que encontrariam em terras estrangeiras.

Ao chegarem às fazendas, alguns japoneses surpreenderam-se com a precariedade das moradias que lhes foram oferecidas. Suas casas eram praticamente sem mobílias, os novos habitantes tinham que providenciar camas, colchões, mesas, cadeiras e armários. Houve ainda aqueles que não possuíam utensílios para preparar seus alimentos, pois suas bagagens foram entregues com atraso. A saída foi recorrer à ajuda de brasileiros que, apesar da boa vontade, serviam comidas muito gordurosas, o que para muitos japoneses pareciam intragáveis.

A quem deveriam reclamar sobre a sua situação? E como seriam compreendidos se sabiam apenas falar japonês? Deviam contar com a ajuda de intérpretes, mas para a sua decepção eram raros os que poderiam ajudá-los efetivamente.

Sobre os trabalhos nos cafezais, os fiscais davam instruções por meio de mímicas e muito esforço para atingir um nível satisfatório de entendimento. Caminhavam para as plantações ao nascer do sol e por vezes regressavam às casas contemplando as estrelas. Durante todo o tempo a presença do fiscal fazia-se constante, levando a alguns japoneses a sentirem-se como prisioneiros. O sistema rígido de trabalho, as insatisfações, a alimentação precária e pouco descanso fizeram com que o serviço nas lavouras parecesse extremamente penoso para os japoneses, principalmente para aqueles que não se dedicavam à agricultura no Japão. Entre vários imigrantes podiam-se encontrar desde policiais, comerciantes falidos, professores, funcionários públicos, pescadores, prostitutas e gueixas (Handa, 1987:41), todos em busca de enriquecimento rápido e fácil.

$\mathrm{Um}$ sentimento de abandono cresceu em muitos corações, pois se julgavam desamparados e esquecidos. Mas em 1910 foram surpreendidos com boas notícias. Corria entre as fazendas a informação que uma segunda leva de japoneses estava para chegar ao país. Muitos se sentiram "renascer" com a notícia. A despeito dessa alegria a vida continuou difícil, os salários eram baixos, o trabalho abundante e as preocupações incessantes.

A realidade parecia insuportável. O colono preocupava-se em produzir seu próprio alimento para evitar comprar nos armazéns da fazenda, que geralmente cobravam preços abusivos. Grande parte do sofrimento do imigrante japonês decorria da preocupação em economizar o máximo possível para retornar ao Japão assim que pudesse. A esperança de retorno breve ao país de origem motivou a preocupação dos colonos com a educação das crianças. Não queriam que seus filhos crescessem ignorantes, eles deveriam ser educados nos moldes nipônicos para que, quando regressassem, não fizessem "feio" diante dos outros. Dessa maneira, os japoneses não mediram esforços para construírem escolas para seus filhos.

Os imigrantes que vieram nos anos subseqüentes não foram poupados das mesmas inquietações. $\mathrm{O}$ desespero levou famílias inteiras a fugirem das fazendas; outros esperavam pacientemente o término do contrato. Os que partiam buscavam fazendas que oferecessem melhores condições de trabalho, ou desistiam dos cafezais e tentavam a sorte nas cidades. $\mathrm{O}$ sonho de retornar ao Japão, rico e triunfante, tornava-se cada vez mais distante. Pareciam náufragos em um mar de dificuldades.

"O que as pessoas vão dizer?". Essa dúvida, para muitos, fazia com que a sensação de fracasso parecesse pior que qualquer outro tipo de sofrimento. Em situação de extrema penúria, sua honra era uma das poucas coisas que lhes restara e agora parecia escorrer por entre os dedos e pesava como um fardo em suas consciências.

Não obstante o sofrimento e queixas, não paravam de chegar japoneses e dois episódios contribuíram para o crescimento da emigração nipônica. Primeiro, foi em 1923, quando ocorreu um terremoto na região de Kanto-Japão. Eram inúmeros os flagelados, vítimas do terremoto, e a saída do governo foi incentivar a emigração, chegando a se responsabilizar pela totalidade das despesas de viagem em 1924. Outro episódio foi a queda da Bolsa de Nova York em 1929, quando a economia japonesa vivenciou o caos: queda nas exportações, crises no campo, alto número de desempregos, incrementando ainda mais as filas nos navios de emigração. As décadas de 20 e 30 foram os anos de maior fluxo imigratório de japoneses para o Brasil e de maior mobilização dos defensores do antiniponismo.

Com o aumento de japoneses em terras brasileiras, houve uma tendência cada vez maior dos imigrantes em agruparem-se em núcleos exclusivamente nipônicos. Entretanto, a formação das famosas colônias japonesas também foi permeada de sofrimentos. Além do duro trabalho de desmatamento das novas terras adquiridas e instalação de infraestrutura para as casas, o que a princípio parecia ser um bom lugar para viver, em pouco tempo, podia transformar-se em um inferno. 
Existem relatos de núcleos de colonização que foram fustigados pela malária - às vezes famílias inteiras desapareciam devido a doença -; outras localidades perderam suas plantações por causa de enchentes ou ataques de gafanhotos.

E quando, enfim, os colonos começaram a vislumbrar esperança de boas colheitas e considerável conforto, alguns foram surpreendidos por policiais e guardas acusando-os de apropriação indevida das terras, ordenando-lhes que abandonassem o local ou que fossem entender-se com a justiça. Na verdade esses policiais e guardas não visavam expulsar os colonos japoneses; antes estavam interessados em receber algum benefício, isto é, dinheiro (cf. Handa, 1987: 270-271).

Contornadas as dificuldades, os colonos puderam desejar dias melhores. A convivência entre iguais permitiu a concretização de certos anseios, como a construção de escolas em moldes nipônicos e o fortalecimento dos ideais japoneses. E o sentimento nacionalista japonês, em grande parte, foi alimentado como reação ao nacionalismo brasileiro e campanha antinipônica veiculados a partir de 1920 .

Notícias vindas do império desempenhavam importante papel em nutrir os sonhos de vários colonos. $\mathrm{O}$ êxito das investidas militares, como a ocupação da Manchúria ocorrida na década de 30 encheu de júbilo os japoneses. A certeza do poder de sua nação foi reforçada pelas propagandas de ideologias nacionalista e etnocentrista veiculadas pelos militares do Japão, que chegavam aos ouvidos dos imigrantes com o nome de "Área de co-prosperidade da Grande Ásia" liderada pelo Japão militarista.

Porém, as festividades dos imigrantes japoneses logo encontrariam obstáculos. Nos anos 30, Getúlio
Vargas subiu ao poder e ocorreu um recrudescimento do nacionalismo brasileiro. E a impossibilidade de dar voz aos ideais de "amor à pátria", crença no poder militar japonês e a proibição de educar os filhos no sistema japonês desferiram duros golpes nas almas dos colonos e em sua estabilidade psíquica.

Numa tentativa desesperada de encontrarem conforto para suas existências (ego) grande parte dos colonos isolou-se ainda mais da sociedade brasileira, cultivando entre eles as sagradas convicções de súditos do Império do Sol Nascente - como ideais de honra e vitórias bélicas. A entrada do Japão na segunda guerra mundial exaltou ainda mais os discursos dos defensores da pátria nipônica. Todos os nacionalistas estavam certos que o seu país sairia vitorioso do confronto, conquistando novas terras e poderes. Nos devaneios da onipotência narcísica, assim que terminassem as lutas, não tardariam, em chegar ao Brasil, delegações japonesas para buscarem os sofridos "filhos" da nação vitoriosa. Os representantes do governo imperial castigariam aqueles que maltrataram os imigrantes durante o tempo em que eles permaneceram em terra estrangeira.

As vidas de muitos colonos japoneses eram tão dolorosas que não puderam conter expectativas e idealizações. As fantasias foram incorporadas às suas realidades e às suas existências. Para os imigrantes nacionalistas, viver só passou a fazer sentido sob a luz desses ideais, dessa fantasia. Perder era inimaginável, impossível.

Quando souberam da derrota do império para as tropas americanas, os imigrantes japoneses não conseguiram compreender, qualificar ou expressar essa dor. Poucos foram os que conseguiram tolerar tamanha frustração.
Grande parte dos membros da colônia preferiu não acreditar na derrota. Alguns acreditavam que essa notícia era propaganda enganosa norteamericana.

Resistiram o quanto puderam. Ocorreram mortes entre os colonos os que defendiam a vitória japonesa chegaram a matar outros japoneses que reconheciam a derrota do país 5 . Causaram perplexidade na sociedade brasileira. E apenas o tempo conseguiu superar essa forte convicção, diluindo os estranhamentos culturais, diminuindo a distância entre japoneses e brasileiros e levando, gradativamente, imigrantes e descendentes nipônicos a reinventarem suas próprias identidades.

\section{* Marcela Jussara Miwa é Mestre em Ciência Política/UNICAMP.}

\section{NOTAS}

1 - Muitos desses médicos antinipônicos compunham a Liga Brasileira de Higiene Mental.

2 - Entre 1927 a 1930 o Japão enviou ao Brasil mais de 10.000 emigrantes por ano. (cf. Handa, 1987: 76-77).

3 - Xavier de Oliveira juntamente a outros médicos, como Renato Kehl, formavam o que pode ser considerada a ala dos "racistas ortodoxos".

4 - Durante o período feudal, o Japão vivenciou a era dos shogunatos, clãs familiares que concentravam o poder político-administrativo no país. Essa época ficou famosa por uma forte categoria de guerreiros, os samurais, que significa "aquele que serve ou acompanha um superior" (cf. Yamashiro, 1993).

5 - Os japoneses que defendiam a vitória nipônica geralmente faziam parte de "sociedades secretas" formadas pelos próprios colonos. Essas sociedades, em sua maioria, visavam enaltecer o poder do império japonês e cultivar os ideais orientais. Existiam aquelas mais exaltadas, como o Movimento Shindo Renmei (Liga do Caminho dos Súditos) que se responsabilizou pelas mortes dos japoneses que admitiam as derrotas (também chamados de 
"derrotistas"). Para alguns dos seus membros, os derrotistas não eram bons japoneses, desrespeitavam o império, e por isso deveriam ser mortos. Importante ressaltar que os conflitos envolvendo essas associações limitavam-se aos membros das colônias japonesas, não representando ameaças aos brasileiros que divulgavam a vitória americana.

\section{REFERÊNCIAS}

Arquivo do Estado de São Paulo. Niponismo. Prontuário $n^{\circ} 8342,2$ volumes. São Paulo.

HANDA, Tomoo

(1980) Memórias de um imigrante japonês no Brasil. São Paulo: T. A. Queiroz/Centro de Estudos NipoBrasileiros.

HANDA, Tomoo

(1987) O imigrante japonês - história de sua vida no Brasil. São Paulo: T.A. Queiroz/Centro de Estudos NipoBrasileiros.

MIWA, Marcela Jussara

(2006) Narciso no império dos crisântemos: interpretando o movimento Shindo Renmei. Dissertação de mestrado em Ciência Política IFCH/UNICAMP. Campinas-SP.

$\mathrm{NUCCI}$, Priscila

(2000) Os intelectuais diante do racismo antinipônico no Brasil: textos e silêncios. Dissertação de mestrado em História - IFCH/UNICAMP. Campinas-SP.

REIS, José Roberto Franco (1994) Higiene mental e eugenia: o projeto de "regeneração nacional" da Liga Brasileira de Higiene Mental (1920-30). Dissertação de mestrado em História - IFCH/UNICAMP. Campinas-SP.

ROSENFELD, Herbert

(1989) "Uma abordagem clínica à teoria psicanalítica das pulsões de vida e de morte: uma investigação dos aspectos agressivos do narcisismo". In: BARROS, Elias M. da Rocha (org.) Melanie Klein: evoluções. São Paulo: Escuta.

SYMINGTON, Neville (2003) Narcisismo: uma nova teoria. São Paulo: Roca.

VIANNA, Oliveira

(1934) Raça e assimilação. São Paulo: Companhia Editora Nacional.

YAMASHIRO, José

(1993) História dos Samurais. São

Paulo: Ibrasa.

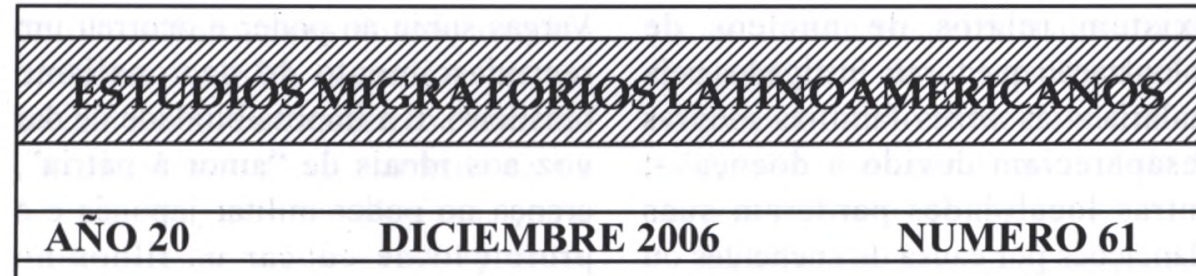

\section{Los Franceses en las Américas}

Presentación

Hernán Otero - François Weil

Las migraciones de Francia hacia las Américas: un objeto de saberes en

el siglo XIX

François Weil

Las políticas de emigración en Francia, 1850-1950

Hernán Otero

¿Dónde están las mujeres? Las francesas y las migraciones a los Estados Unidos (1880-1930)

Annick Foucrier

Los franceses desde el silencio: la población del Panteón francés de la ciudad de México: 1865-1910

Javier Pérez Siller

"Le Courrier de la Plata. Diario republicano francés rioplatense"

Viviane Oteiza Gruss

Alfred Ebelot o la trayectoria migratoria de un francés en Argentina en la segunda mitad del siglo XIX

Pauline Raquillet-Ambrogi

$\begin{array}{lll}\text { AÑO 21 } & \text { ABRIL 2007 } & \text { NUMERO 62 }\end{array}$

Migraciones internacionales y política en Bolivia: passado y presente Eduardo E. Domenech - Maria José Magliano

Economía rural y población: la emigración en áreas de montaña.

Humahuaca y Yavi (provincia de Jujuy) durante el siglo XX

Raquel Gil Montero, Mariano Morales y Mariana Quiroga Mendiola

Migración, comercio y moral en los margenes del mundo salitrero.

Oficina "Chacabuco", 1924-1940

Maria Damilakou

"Ser de Cristo". Prácticas, ideas y recepción del protestantismo entre los sectores populares inmigrantes en Buenos Aires, 1870-1910

Paula Seiguer

Diferentes percursos da migração italiana no Rio Grande do Sul (Brasil) Maria Catarina Chitolina Zanini

www.cemla.com 